\title{
Optimizing Surgical and Imatinib Therapy for the Treatment of Gastrointestinal Stromal Tumors
}

\author{
Jason K. Sicklick • Nicole E. Lopez
}

Received: 7 May 2013 / Accepted: 31 May 2013 / Published online: 18 June 2013

(C) 2013 The Author(s). This article is published with open access at Springerlink.com

\begin{abstract}
Introduction The discovery of activating KIT and PDGFR $\alpha$ mutations in gastrointestinal stromal tumors (GISTs) represented a milestone as it allowed clinicians to use tyrosine kinase inhibitors, like imatinib, to treat this sarcoma. Although surgery remains the only potentially curative treatment, patients who undergo complete resection may still experience local recurrence or distant metastases. Therapeutic strategies that combine surgical resection and adjuvant imatinib may represent the best treatment to maximize patient outcomes. In addition to the use of imatinib in the adjuvant and metastatic settings, neoadjuvant imatinib, employed as a cytoreductive therapy, can decrease tumor volume, increase the probability of complete resection, and may reduce surgery-related morbidities. Thus, selected patients with metastatic disease may be treated with a combination of preoperative imatinib and metastasectomy. However, it is critical that patients with GIST be evaluated by a multidisciplinary team to coordinate surgery and targeted therapy in order to maximize clinical outcomes.

Discussion Following a systematic literature review, we describe the presentation, diagnosis, and treatment of GIST, with a discussion of the risk assessment for imatinib therapy. The application of surgical options, combined with adjuvant/neoadjuvant or perioperative imatinib, and their potential impact on survival for patients with primary, recurrent, or metastatic GIST are discussed.
\end{abstract}

Keywords Gastrointestinal stromal tumor · GIST · Imatinib · Tyrosine kinase inhibitor · Outcomes

\section{Introduction}

Gastrointestinal stromal tumors (GISTs) are the most common type of mesenchymal tumors of the gastrointestinal tract. The estimated prevalence of GIST is $12-20$ cases per million, with an estimated annual incidence of 6,000 cases in the USA. ${ }^{1,2}$ Approximately $70-80 \%$ of sporadic GISTs are caused by gain-of-function mutations in KIT, whereas 5$10 \%$ are caused by gene mutations, deletions, or insertions that activate platelet-derived growth factor receptor alpha $(P D G F R \alpha) .{ }^{3,4}$ Another $10-15 \%$ are wild type (WT) for

\footnotetext{
J. K. Sicklick $(\bowtie) \cdot$ N. E. Lopez

Division of Surgical Oncology, Department of Surgery, Moores

UCSD Cancer Center, University of California, San Diego, UC San

Diego Health System, 3855 Health Sciences Drive, Mail Code

0987, La Jolla, CA 92093-0987, USA

e-mail: jsicklick@ucsd.edu

N. E. Lopez

e-mail:n1lopez@ucsd.edu
}

KIT and PDGFR $\alpha$ but may contain mutations in BRAF (including up to $15 \%$ with the V600E mutation) or succinate dehydrogenase $(\sim 2 \%)^{3-5}$

Surgery is the primary treatment for resectable GIST, but this approach is not always curative. Although complete (R0) resection can be achieved in up to $85 \%$ of patients with primary disease, approximately $50 \%$ of patients develop recurrences or metastases within 5 years of primary resection. ${ }^{6}$ Thus, prior to the advent of tyrosine kinase inhibitor (TKI) therapy, the 5-year recurrence-free survival (RFS) rate remained at only $45-65 \% .{ }^{6,7}$ The TKI, imatinib, which selectively inhibits the KIT receptor, has demonstrated clinical benefit for patients with GIST. In clinical trials, imatinib treatment resulted in response rates of 40-55\%, improved progression-free survival (PFS) for patients with KIT-positive unresectable or metastatic GIST, ${ }^{8-11}$ and extended RFS and overall survival (OS) in the adjuvant setting. ${ }^{12,13}$ Accordingly, imatinib is currently approved as first-line treatment in both settings. ${ }^{14}$

Treatment of GIST depends on several factors such as the presence of metastases, expected difficulty of surgery, size of the primary tumor, and overall health of the patient. The judicious use of surgery and imatinib therapy is essential to 
maximizing patient outcomes in GIST. Herein, we discuss how the optimal use of surgery (for primary tumors and metastases) in combination with neoadjuvant/preoperative and adjuvant/postoperative imatinib can improve clinical outcomes and may extend survival.

\section{Methods}

We performed a systematic review of published medical literature (PubMed) for English-language articles based on the following search terms: gastrointestinal stromal tumor (GIST); GIST and surgery; GIST and resection; GIST and metastasectomy; GIST and imatinib; and imatinib and adjuvant or neoadjuvant therapy. Selected relevant abstracts from key oncology meetings were also reviewed.

\section{GIST Presentation and Diagnosis}

GISTs primarily arise in the stomach (60\%) and small intestine $(35 \%)$, with fewer than $5 \%$ occurring in the esophagus, mesentery, omentum, and rectum. Rarely, cases occur outside of the GI tract. ${ }^{15}$ Although metastases are mostly hepatic and peritoneal-based (Fig. 1), they can also develop extra-abdominally late in the disease. ${ }^{16}$

Small GISTs $(<2 \mathrm{~cm})$ are usually asymptomatic and detected incidentally during endoscopy, surgery or physical examination $(21 \%)$, or autopsy $(10 \%) .{ }^{5,17}$ However, most GISTs (69\%) are diagnosed at the time of presentation with nonspecific symptoms such as nausea, vomiting, early satiety, melena and anemia (due to bleeding caused by intraluminal erosion or intraperitoneal rupture), abdominal pain, distension, fever, or leukocytosis. ${ }^{5,18}$

GISTs originate in the muscularis propria, likely originating from the interstitial cells of Cajal. Most GISTs present as a single endophytic or exophytic nodule with a well-defined border and a median size of 3-5 cm (range of a few millimeters to $\geq 35 \mathrm{~cm}$ ). ${ }^{5}$ They rarely invade adjacent structures, but penetration through the bowel wall, organ invasion, adenopathy, cystic degeneration, irregular margins, mesenteric fat infiltration, ulceration, hemorrhage, and necrosis likely indicate malignancy. GISTs are also highly vascular (Fig. 2) and friable. Thus, they are prone to rupture and dissemination, which greatly increase the risk of recurrence. ${ }^{19}$

Histologically, GISTs can have spindle (70 \%), epithelioid $(20 \%)$, or mixed cellular morphologies $(10 \%)$. Because spindle and epithelioid GISTs can be confused with many other tumor types (e.g., leiomyoma, schwannoma, sarcomatoid carcinoma), a suspected diagnosis of GIST should be confirmed by immunohistochemical staining. ${ }^{5}$ Markers typically include KIT (c-KIT, CD117), CD34, and $\alpha$-smooth muscle actin, which stain positive in 95,70 , and $30-40 \%$ of cases,
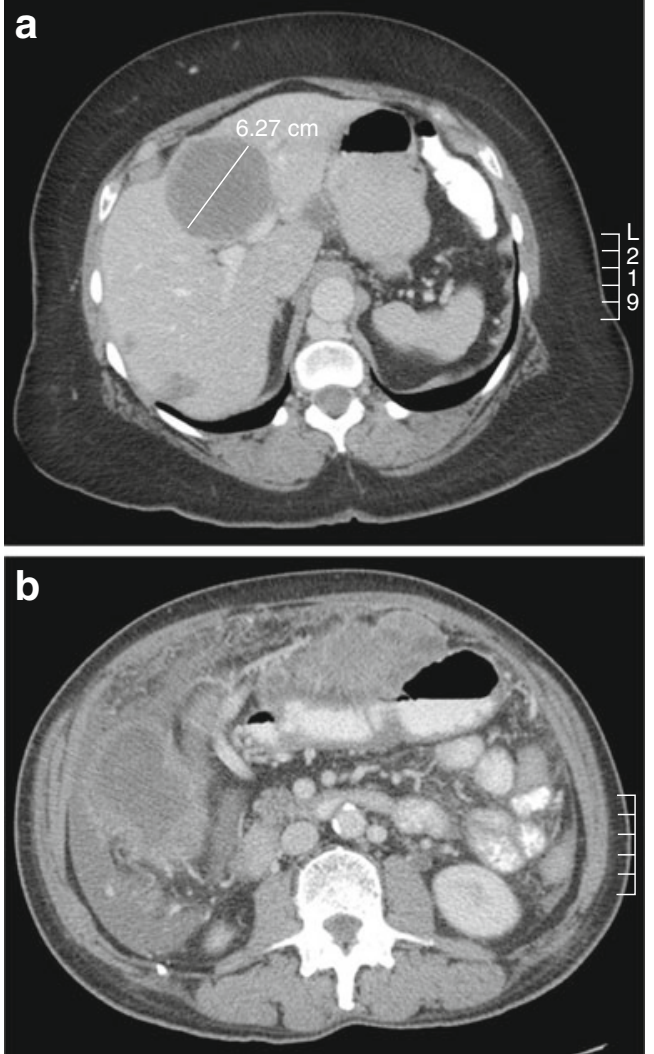

Fig. 1 GIST metastatic spread is typically hematogenous, with metastases occurring mainly to the liver (a) and peritoneum (b)

respectively. The discovered on GIST1 (DOG1) marker can facilitate the diagnosis of KIT-negative GISTs since $92 \%$ are DOG1-positive. ${ }^{5,20,21}$

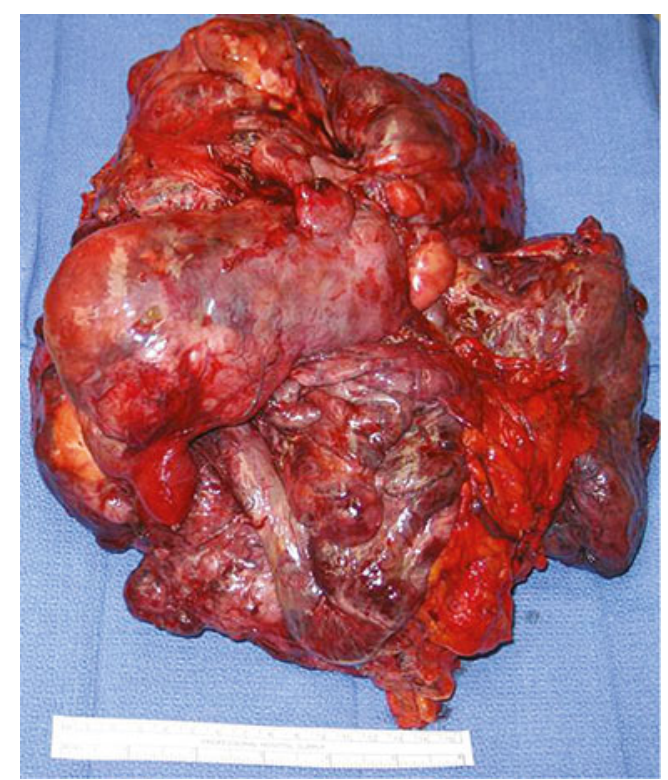

Fig. 2 Many GISTs are or become hypervascular, as shown in this pathologic specimen 


\section{Imaging of GIST}

Endoscopic ultrasound (EUS), computed tomography (CT) with contrast enhancement, magnetic resonance imaging (MRI), and positron emission tomography (PET) can be used to image suspected GISTs, characterize extent of disease, and assess response to therapy.

The endoscopic characteristics of GISTs include smooth shape, normal overlying mucosa, occasional mucosal ulceration, and firm consistency on compression (Fig. 3). ${ }^{22}$ However, standard endoscopy cannot reliably determine the size of these submucosal lesions nor provide adequate biopsy samples using standard forceps. ${ }^{23}$ EUS can determine additional lesion features, including hypoechoic appearance, oval shape, and wall layer of origin, which may aid in diagnosing GIST and determining malignant features. ${ }^{24,25}$ EUS-guided tissue acquisition for histological analysis is now preferred for GISTs because it provides adequate material for histologic and mutational analyses ${ }^{26}$ with a diagnostic accuracy of $\sim 80 \%{ }^{27-29}$ Moreover, endoscopic ultrasoundguided fine-needle aspiration (EUS-FNA) is preferred over percutaneous biopsy due to its lower risk of hemorrhage and tumor seeding. ${ }^{30}$ More recently, the utility of endoscopic ultrasound-guided Tru-Cut biopsy (EUS-TCB) for GISTs

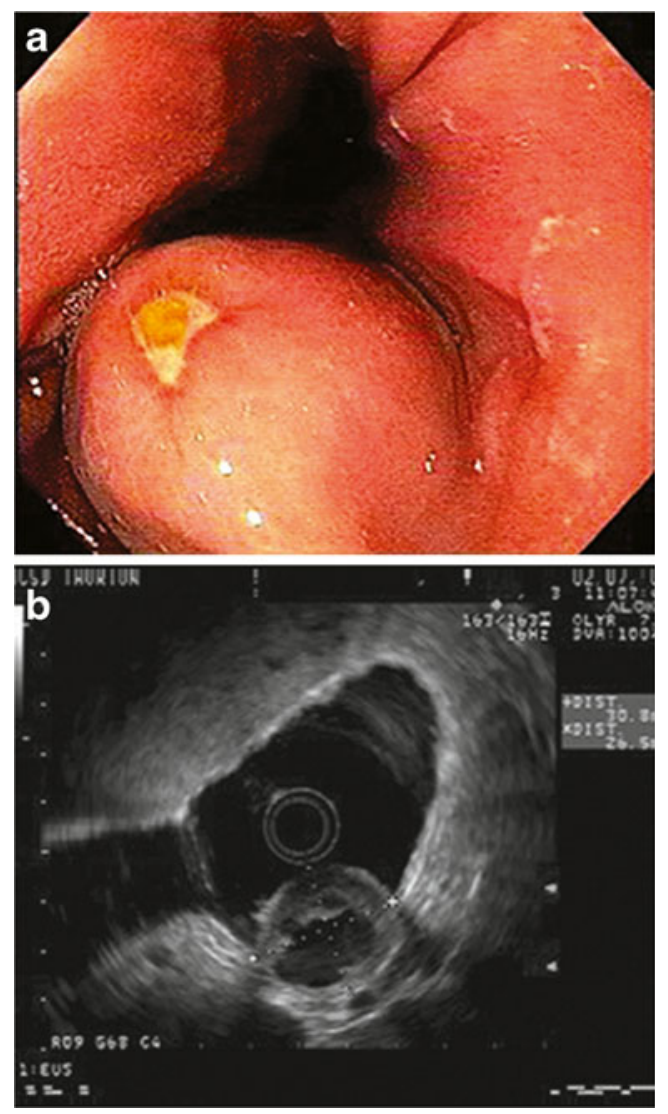

Fig. 3 Endoscopy image of an ulcerated proximal gastric GIST (a) and corresponding EUS (b) (images courtesy of Dr. Thomas Savides) was evaluated in six patients to obtain specimens for pathological and immunohistochemical studies. ${ }^{31}$ All tumors were $>2 \mathrm{~cm}$, and core tissue samples were successfully procured in all cases. The final diagnosis was KIT-positive GIST in five patients and leiomyoma in one patient. No patients developed complications after the procedure, suggesting that EUS-TCB is safe. Additionally, EUS-TCB is faster to perform than endoscopic mucosal biopsy, providing sufficient tissue for pathological diagnosis. $^{31}$

Contrast-enhanced $\mathrm{CT}$ is the best radiological technique for the characterization of GISTs and for the evaluation of the extent of disease. ${ }^{32}$ Typically, GISTs appear as hyperdense, enhancing masses on CT. When present, calcification, ulceration, necrosis, cystic areas, fistula, metastases, ascites, and infiltration indicate malignancy. ${ }^{33}$ The limitations of CT include the inability to accurately identify the bowel wall layers involved and difficult analysis of small lesions. ${ }^{22}$ MRI provides higher sensitivity for small liver lesions and should be used to evaluate liver metastases or when CT is inconclusive or contraindicated. ${ }^{34}$ MRI also offers good soft tissue contrast and may be best for imaging retrorectal tumors. ${ }^{35}$

Most GI malignancies are metabolically active and take up the radiolabeled glucose analog ${ }^{18} \mathrm{~F}$-fluorodeoxyglucose $\left({ }^{18} \mathrm{FDG}\right)$, making ${ }^{18} \mathrm{FDG}$-PET a highly sensitive and valuable imaging tool for diagnosis and a predictor of clinical outcome (Fig. 4). ${ }^{22}$ The overall sensitivity of ${ }^{18}$ FDG-PET is approximately $80 \%$ in detecting GISTs at initial presentation. ${ }^{20}$ Unfortunately, GISTs exhibit variable ${ }^{18}$ FDG uptake, ${ }^{36,37}$ and only some tumors are ${ }^{18}$ FDG-avid. ${ }^{18}$ FDG-PET is thus typically reserved for resolving ambiguous findings on $\mathrm{CT}$ or MRI (e.g., increase in size due to pseudo-progression versus true tumor progression) and for monitoring early response to imatinib treatment by serial scans. In phase II trials, ${ }^{18}$ FDGPET revealed responses within the first 1-7 days of treatment in $69-85 \%$ of patients, supporting its use to monitor early response to imatinib. ${ }^{38,39}$ Decreases in FDG uptake, as measured by changes in $\mathrm{SUV}_{\max }$, can occur as early as $24 \mathrm{~h}$ after imatinib treatment. ${ }^{20}$ At present, however, there are no standardized criteria for PET response for GIST, and this is an area of active research.

\section{Biology Dictates Treatment}

Patients with suspected GIST should be evaluated by a multidisciplinary team with expertise in sarcoma, as recommended by current National Comprehensive Cancer Network (NCCN) and European Society of Medical Oncology (ESMO) guidelines. They should undergo a thorough workup, including imaging and biopsy (unless biopsy will not change the decision to operate), to obtain an accurate diagnosis and determine the optimal treatment. ${ }^{14,26}$ The prognosis of patients with primary tumors varies depending upon 


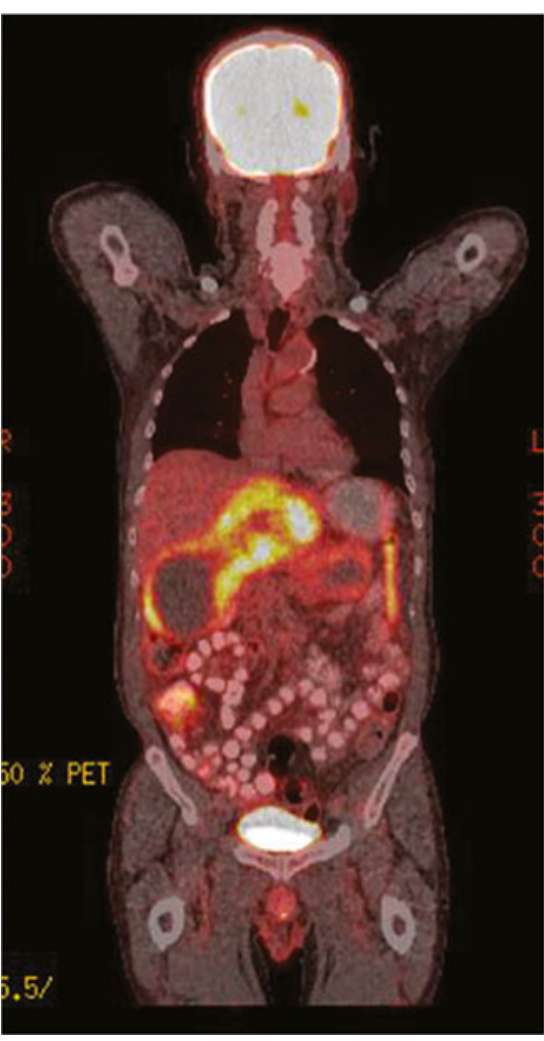

Fig. $4{ }^{18}$ FDG-PET scan of a patient with ${ }^{18}$ FDG-avid metastatic GIST showing significant uptake of this marker

tumor size, mitotic index (MI, mitoses per 50 high-power fields [HPF] equals $5 \mathrm{~mm}^{2}$ ), and location. ${ }^{15,40}$ In an analysis of pooled, population-based cohorts involving 2,560 patients with operable GIST, independent adverse prognostic factors included tumor rupture and male gender, in addition to large tumor size, high MI, and non-gastric location. ${ }^{41}$

For GISTs $\leq 2 \mathrm{~cm}$ in size, abdominal/pelvic CT and/or MRI should be performed to determine tumor location and possible presence of metastatic disease. ${ }^{14,26,30}$ Biopsy should be obtained by EUS-FNA or core needle to confirm diagnosis and identify potential high-risk features (e.g., irregular border, cystic spaces, ulceration, echogenic foci, heterogeneity, MI $\geq 5 / 50 \mathrm{HPF}$ ). Patients without high-risk features may be followed up by endoscopic surveillance for signs of transformation or until they become symptomatic. However, all rectovaginal GISTs require biopsy/excision, regardless of size, due to their increased risk of morbidity. ${ }^{30}$ A biopsy by endorectal EUS is also recommended to screen for imatinib-resistant genotypes (e.g., WT GISTs, PDGFR $\alpha$ D842V mutation) to avoid unnecessary drug-related toxicity and ineffective therapy. ${ }^{14,26}$ If EUS-guided biopsy is not feasible, laparoscopic or open resection can be performed.

For resectable GISTs $>2 \mathrm{~cm}$, abdominal/pelvic CT and/or MRI are also recommended to identify potential metastases and determine surgical risk. Resection is the preferred primary treatment for localized GISTs $>2 \mathrm{~cm}$, with a goal of R0 margins, intact pseudocapsule, no tumor rupture, and minimal morbidity. Postsurgical pathology is important to confirm GIST diagnosis. ${ }^{14,26}$ The pathology report should detail anatomic location, tumor morphology, size, MI (determined from the most proliferative area), and the presence/absence of tumor rupture. ${ }^{30}$

\section{Surgical and Systemic Treatment Options}

Surgical options for GISTs range from minimally invasive endoscopic techniques for small tumors to open surgery for large malignancies. The goal of surgical treatment for GIST is complete gross resection (i.e., negative microscopic margins and intact pseudocapsule without tumor rupture). Because lymph node metastases are uncommon, lymphadenectomy is not generally indicated. Gastric GISTs located away from the gastroesophageal junction may be adequately resected with a gastric wedge resection, rather than by gastrectomy with lymphadenectomy. The lack of need for lymphadenectomies, combined with advances in minimally invasive techniques, has resulted in wider acceptance of minimally invasive approaches for resecting larger GISTs. ${ }^{42-44}$ Table 1 summarizes the advantages and disadvantages of various surgical procedures for GIST resection. For example, endoscopic submucosal resection with negative margins may not be attainable in all patients, and this technique has been associated with high rates of margin positivity and perforation, compared with other procedures. ${ }^{45-49}$ Regardless of the chosen method, capsule disruption and/or tumor rupture should be avoided during surgery to minimize the risk of recurrence. ${ }^{50}$

Laparoscopic techniques are well-established for the resection of gastric GISTs ranging from a mean of 3.4 to $10 \mathrm{~cm}$ without additional risk of complications or recurrence. ${ }^{42-44,51-57}$ Current guidelines suggest laparoscopy for tumors located in the anterior wall of the stomach, jejunum, or ileum. ${ }^{58}$ Several case reports have also shown that combined laparoscopic and endoscopic techniques can be used successfully to resect GISTs. ${ }^{59-61}$

Compared with laparoscopic surgery, laparotomy allows for additional exposure, visualization, and mobilization of larger tumors. ${ }^{62-64}$ Although no differences in recurrence rates have been reported between laparoscopic procedures and laparotomy, the latter has been associated with longer postoperative hospital stays, greater blood loss, and longer operation time. However, this may reflect a selection bias because large tumors may not be resectable by minimally invasive approaches.

\section{Adjuvant Imatinib Therapy}

Imatinib can further improve patient outcomes when used as adjuvant therapy. The randomized, double-blind, placebo- 
Table 1 Relative advantages and disadvantages of surgical options for primary GISTs

\begin{tabular}{|c|c|c|c|c|}
\hline Surgical technique & Advantages & $\begin{array}{l}\text { Limitations } \\
\text { (evidence) }\end{array}$ & $\begin{array}{l}\text { Tumor } \\
\text { location }\end{array}$ & Disadvantages \\
\hline Endoscopy ${ }^{45-49}$ & $\begin{array}{l}\text { Minimally invasive; potentially } \\
\text { shorter operation time }\end{array}$ & $\begin{array}{l}\text { Small series; } \\
\text { retrospective } \\
\text { study }\end{array}$ & $\begin{array}{l}\text { Esophagus; } \\
\text { stomach; } \\
\text { rectum }\end{array}$ & Often leaves positive margins \\
\hline Laparoscopy ${ }^{42-44,51-57}$ & $\begin{array}{l}\text { Full-thickness resection of stomach wall; } \\
\text { negative margins; minimal risk of } \\
\text { dissemination; shorter hospital stay }\end{array}$ & $\begin{array}{l}\text { Small studies } \\
\qquad(n=4-61)\end{array}$ & $\begin{array}{l}\text { Stomach; } \\
\text { small bowel }\end{array}$ & $\begin{array}{l}\text { Can be technically challenging } \\
\text { with larger tumors }\end{array}$ \\
\hline Laparoendoscopy ${ }^{59-61}$ & $\begin{array}{l}\text { Monitor endoscopic resection; } \\
\text { repair injury/perforation }\end{array}$ & Case reports & $\begin{array}{l}\text { Stomach; } \\
\quad \text { duodenum }\end{array}$ & \\
\hline Laparotomy ${ }^{62,63}$ & $\begin{array}{l}\text { Better visualization and mobilization of larger } \\
\text { tumors or those in technically challenging } \\
\text { locations }\end{array}$ & $\begin{array}{l}\text { Small case series; } \\
\text { retrospective } \\
\text { studies }\end{array}$ & Stomach & $\begin{array}{l}\text { Longer hospital stay; } \\
\text { potentially more blood loss; } \\
\text { potentially longer operation } \\
\text { time }\end{array}$ \\
\hline
\end{tabular}

controlled American College of Surgeons Oncology Group Z9001 phase III study was conducted to assess the survival benefit of 1 year of adjuvant therapy with imatinib (400 $\mathrm{mg}$ /day) in patients with high risk of recurrence following complete resection of primary GIST. Adjuvant imatinib significantly reduced GIST recurrence in patients with tumors $\geq 3 \mathrm{~cm}$ in size: the 1-year RFS rate was $98 \%$ with imatinib versus $83 \%$ with placebo $(P<0.0001){ }^{12}$ Analysis at 4-year follow-up showed no difference in RFS for patients undergoing R1 versus R0 resection, regardless of whether they received adjuvant imatinib (hazard ratio [HR], 1.095; $95 \%$ confidence interval $[\mathrm{CI}], 0.66-1.82 ; P=0.73$ ) or placebo (HR, 1.51; $95 \%$ CI, $0.76-2.99 ; P=0.24) .{ }^{50}$ These data suggest that factors beyond margin status, such as rupture and tumor location, may also be critical for predicting recurrence.

Subsequently, to explore whether increasing duration of imatinib therapy would result in improved RFS at long-term follow-up, the open-label Scandinavian Sarcoma Group/Sarcoma Group of the Arbeitsgemeinschaft Internistische Onkologie (SSGXVIII/AIO) phase III trial randomized patients who underwent gross resection of primary KIT-positive GIST to receive 1 or 3 years of adjuvant imatinib ( $400 \mathrm{mg} /$ day). These patients were judged to be at high risk of recurrence if they had tumors with one or more of the following characteristics: diameter $>10 \mathrm{~cm}$; $\mathrm{MI}>10$ mitoses per 50 HPF; tumor diameter $>5 \mathrm{~cm}$ with $>5$ mitoses per HPF; or tumor rupture before or at surgery. Patients had significantly greater RFS and OS with 3 years adjuvant imatinib versus 1 year of treatment (Fig. 5). At 5-year follow-up, RFS and OS rates were 65.6 and $92.0 \%$ in the 3-year arm versus 47.9 and $81.7 \%$ in the 1 -year arm $(P<0.001$ and $P=0.02)$, respectively. ${ }^{13}$ Accordingly, NCCN guidelines now recommend at least 3 years of adjuvant imatinib treatment for patients with KIT-positive GIST who are at high risk of recurrence based on tumor size, MI, site, rupture, and completeness of surgery. ${ }^{14}$

The risk of GIST recurrence can be predicted based on MI, tumor size and location, and tumor rupture. Various stratification strategies have been developed to quantify the risk of recurrence in patients with primary GIST. ${ }^{40,65-67}$ The 2002 National Institutes of Health (NIH) Fletcher criteria ${ }^{66}$ rely solely on MI and tumor size, whereas the Miettinen-Lasota/Armed Forces Institute of Pathology criteria ${ }^{40}$ also account for tumor location (gastric versus duodenal versus jejunal/ileal versus rectal), defining six risk groups and providing an estimated rate of metastasis or tumor-related death. The modified NIH Fletcher system defines risk by tumor size, location (gastric versus non-gastric), MI, and tumor rupture while identifying subgroups at especially high risk for recurrence. ${ }^{68}$ The Memorial Sloan-Kettering nomogram was derived from 127 patients and validated at two additional centers. It predicts 2- and 5-year RFS after the resection of localized, primary GIST based upon tumor size, location, and MI. ${ }^{65}$ In 2010, the American Joint Committee on Cancer proposed a GIST staging system parallel to that for other soft tissue sarcomas based upon tumor location (gastric versus small intestine), tumor size (T), lymph node metastasis $(\mathrm{N})$, distant metastasis (M), and MI. ${ }^{69}$ Most recently, another method for risk assessment was proposed by Joensuu and colleagues. ${ }^{41}$ Using an observational cohort of 2,560 patients and a validation cohort of 920 patients who had R0/R1 resections, they developed prognostic contour maps that utilize tumor size, location (including extraintestinal GISTs), MI, and tumor rupture to predict 10-year RFS. Additional factors such as KIT, PDGFR $\alpha$, and $B R A F$ mutational status and tumor histology (e.g., spindle versus epithelioid) are being investigated, but are not currently considered for risk assessment. However, there is no standardized risk assessment strategy. Physicians who treat patients with GIST need to ensure that these tools are used routinely and correctly to optimize decisions on the prescription and duration of adjuvant imatinib for eligible patients.

The optimal duration of adjuvant imatinib is still unknown, but two ongoing studies are currently addressing this question. The European Organization for Research and Treatment of Cancer 62024 trial (ClinicalTrials.gov identifier: NCT00103168) is a randomized, phase III study of 2 years of imatinib therapy in patients with GIST at intermediate or high 
a

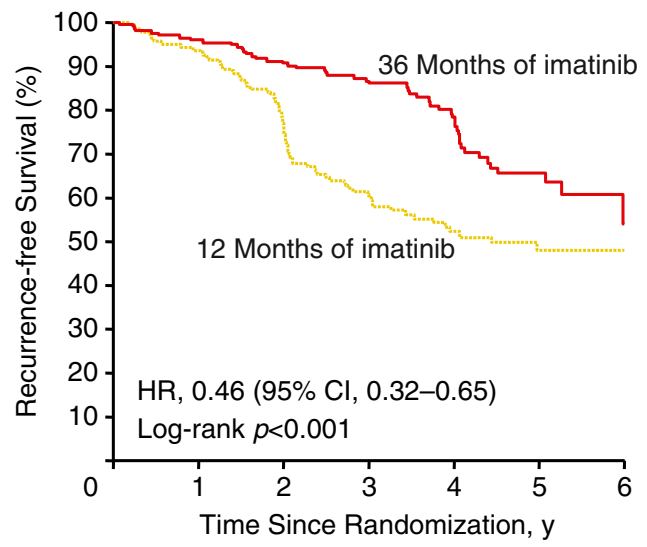

No. of patients

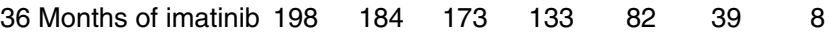

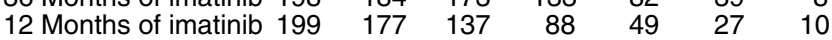

b

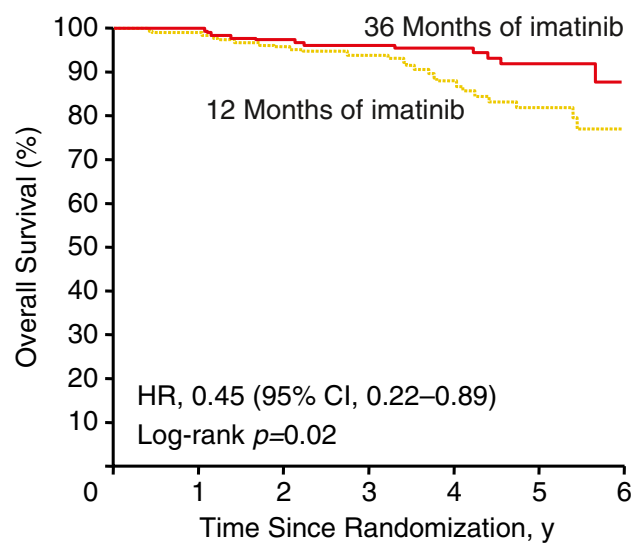

No. of patients

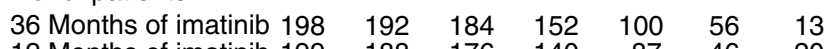

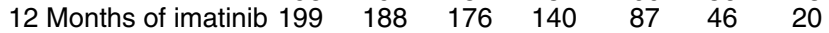

Fig. 5 RFS (a) and OS (b) in patients with primary GIST treated with 1 versus 3 years of adjuvant imatinib in the SSGXVIII/AIO phase III trial ${ }^{13}$

risk of recurrence following resection, with a 5-year followup. PERSIST-5 (ClinicalTrials.gov identifier: NCT00867113) is a phase II trial evaluating up to 5 years of imatinib in patients at significant risk of GIST recurrence following complete resection. Results from these trials will provide additional information regarding the long-term use of adjuvant imatinib.

\section{Neoadjuvant/Preoperative Imatinib Therapy for Locally Advanced/Metastatic GIST}

Neoadjuvant/preoperative imatinib therapy may reduce the risk of surgical morbidity and improve the probability of achieving complete resection. Several studies support its use in patients with potentially resectable primary or metastatic GIST. Tielen et al. evaluated 57 patients with locally advanced primary GIST who received neoadjuvant imatinib for a median 8 months. ${ }^{70}$ Imatinib caused tumor reduction (median, $49 \%$ ) and enabled R0 resection in $84 \%$ of patients, with no tumor rupture; 5-year PFS and OS rates were 77 and $88 \%$, respectively. ${ }^{70}$ Additionally, in patients with advanced primary GIST who received neoadjuvant imatinib for up to 12 months, 11 out of 14 (79\%) subsequently underwent complete resection (4-year OS, $100 \%$; 4-year disease-free survival, $64 \%$; follow-up, 48 months). ${ }^{71}$ Neoadjuvant imatinib can also facilitate resection of borderline resectable primary GIST. $^{72}$ Thus, neoadjuvant imatinib can be employed for treating borderline or initially unresectable tumors in the gastroesophageal junction, duodenum, or rectum.

In another study, 55 patients with metastatic GIST underwent surgery after a median 16 months of TKI therapy (range, 3-72 months). ${ }^{73}$ At the time of surgery, the rate of tumor recurrence or progression was lower in patients who responded to preoperative TKI therapy (48\%) than in those who did not $(85 \%)$. Although nearly all patients who undergo excision of metastases ultimately experience recurrence, ${ }^{32}$ initial response to combined preoperative TKI therapy and complete resection correlated with improved PFS and OS. ${ }^{73}$

These retrospective results suggest that patients with advanced primary or metastatic/recurrent GIST may have improved outcomes with surgical resection if they respond to neoadjuvant/preoperative imatinib as compared to those patients who have progressive disease on therapy. Unfortunately, prospective trials comparing imatinib plus surgery versus surgery alone have failed to accrue patients. Therefore, the additional benefit of surgery over imatinib alone is still unproven. Despite a lack of prospective data, neoadjuvant/preoperative imatinib (starting dose, $400 \mathrm{mg} /$ day) is recommended by the NCCN (duration based on tumor response, generally 6-12 months) and ESMO guidelines as an option in patients with large, localized GISTs in which resection carries significant risk of morbidity/functional deficit and in those with poorly positioned tumors that are marginally resectable, unresectable, recurrent, or metastatic. ${ }^{14,30}$ Presently, however, this is not an approved indication for neoadjuvant/preoperative imatinib (or other TKIs) for GIST.

\section{Surgical Resection of Recurrent or Metastatic GISTs}

Approximately $50 \%$ of patients who undergo GIST resection will develop recurrent disease, ${ }^{6}$ at which time approximately two thirds will have liver metastases and half will have peritoneal disease (Fig. 1). ${ }^{32}$ Liver metastases are usually multifocal, but approximately $25 \%$ are candidates for resection.

Combined with perioperative imatinib therapy, metastasectomy can be effective in some patients. ${ }^{74}$ In a retrospective study, seven patients with advanced/recurrent GIST underwent radical resection of liver $(n=4)$, peritoneum $(n=1)$, liver and peritoneum $(n=1)$, or liver and lymph node $(n=1)$ metastases 
upon best response to preoperative imatinib; imatinib was then continued for a median of 26 months. The 2-year PFS was $64.4 \%$. $^{75}$

Perioperative imatinib can also improve outcomes in metastasectomy patients who present with metastatic GIST. ${ }^{76}$ DeMatteo et al. reported increased 2-year PFS (61\%) and OS $(100 \%)$ rates in patients with metastatic GIST who responded to perioperative imatinib. In contrast, 2-year PFS and OS rates were 0 and $36 \%$, respectively, in patients who did not respond. ${ }^{77}$ Another study showed that, for patients who underwent surgical debulking in the context of perioperative TKI therapy, the 1 -year PFS rates were 80,33 , and $0 \%$ for patients with stable disease (SD), limited progression, and generalized progression, respectively $(P<0.0001)$, whereas the 1 -year OS rates were 95,86 , and $0 \%$, respectively $(P<0.0001) .{ }^{80}$ In another study, patients with metastatic GIST who were treated with perioperative TKI therapy and partial hepatectomy had an OS rate of 96.7, 76.8, and 67.9\% at 1, 2, and 3 years, respectively. The median OS was not reached at 5 years. ${ }^{74}$ Long-term follow-up of patients with GIST who underwent metastasectomy in the context of perioperative imatinib treatment revealed a median OS of 8.7 years for $\mathrm{R} 0 / \mathrm{R} 1$ resections, compared with 5.3 years for $\mathrm{R} 2$ resections $(P=0.0001){ }^{78}$ Moreover, median survival was not reached in R0/R1 patients with hepatic-only metastases compared with 8.7 and 5.9 years in patients with peritoneal $(P=0.064)$ versus peritoneal and hepatic metastases $(P=0.001$ and $P=0.024) .^{78}$

In the prospective phase II Radiation Therapy Oncology Group 0132 trial, the safety and efficacy of neoadjuvant/preoperative imatinib (600 mg/day for 8-12 weeks) were evaluated in patients who underwent resection of advanced primary (group A, $n=30$ ) or metastatic (group B, $n=22$ ) GIST, followed by adjuvant/postoperative imatinib for 2 years. ${ }^{79}$ In group A, $7 \%$ of patients had a partial response (PR) and $83 \%$ had SD, compared with $4.5 \% \mathrm{PR}$ and $91 \% \mathrm{SD}$ in group B. The 2-year PFS rate was $83 \%$ in group A versus $77 \%$ in group B, and the estimated rate of OS was $93 \%$ in group A versus $91 \%$ in group B. Surgical complications and imatinib toxicity were minimal, suggesting that combining perioperative imatinib with surgery is both feasible and safe for patients with advanced or metastatic GIST. ${ }^{79}$ At 5-year follow-up, RFS and OS rates were 57 and $77 \%$ in group A, respectively. Six of seven relapses occurred after patients discontinued adjuvant imatinib. ${ }^{80}$ In group B, PFS and OS rates were 30 and $68 \%$, respectively. Six of ten relapses also occurred after discontinuation of adjuvant imatinib. Importantly, there was no increase in long-term surgical complications compared with the initial report.

Lastly, the role of surgery in patients with metastatic/recurrent GIST who exhibited at least 6 months of SD or response while taking imatinib has been evaluated. At a median follow-up of 58.9 months, median OS was not reached in patients who underwent surgery $(n=42)$, compared with 88.8 months in those who did not undergo surgery $(n=92)$, with PFS values of 87.7 and 42.8 months, respectively ( $P=0.001$ for both). ${ }^{81}$

Overall, these results suggest that combining surgery with perioperative imatinib therapy can be more effective than either treatment alone in patients with advanced primary GIST, as well as those with recurrent or metastatic GIST, provided the disease is responsive to imatinib.

\section{Future Directions and Conclusions}

Technical advances now allow access to enhanced imaging and advanced minimally invasive surgical techniques for many patients, hence facilitating tumor visualization and diagnosis, pathologic and mutational analyses, and treatment to improve recovery and outcomes. Surgical decisionmaking based on tumor genetics and responsiveness to TKIs is expected to evolve further. Meanwhile, the increasing safety ${ }^{51,82-85}$ and oncologic integrity ${ }^{86}$ of laparoscopic GIST resections encourage further exploration of minimally invasive options, such as robotic surgery, ${ }^{87-89}$ transanal minimally invasive surgery, ${ }^{90}$ and fluorescent-guided imaging during surgery. ${ }^{91}$

Results of ongoing trials will undoubtedly provide additional insights into the synergy of surgery and imatinib therapy and bring us closer to determining optimal treatment regimens for patients with GIST. Regardless, current evidence supports the combined use of surgery and perioperative imatinib because its impact on patient outcomes can be greater than either treatment alone. Surgical resection of metastases may even allow prolonged or complete remission in patients who respond to neoadjuvant imatinib and continue imatinib therapy afterwards. However, it is critical that patients be evaluated by a multidisciplinary team with expertise in GIST to coordinate surgery and therapy, as well as to ensure maximal clinical benefits over the entire course of the disease.

Acknowledgments Medical writing assistance was provided by Michele Jacob, Ph.D., and Larry Rosenberg, Ph.D., CMPP, of Evidence Scientific Solutions, which was supported by Novartis Pharmaceuticals Corporation.

Conflict of Interest Jason Sicklick received honorarium from Novartis Pharmaceuticals Corporation for advisory board consultancy and speaker training, as well as reimbursement for travel, lodging, and meals.

Ethical Guidelines No patient studies or hazardous procedures were required to prepare this article.

Open Access This article is distributed under the terms of the Creative Commons Attribution License which permits any use, distribution, and reproduction in any medium, provided the original author(s) and the source are credited. 


\section{References}

1. Goettsch WG, Bos SD, Breekveldt-Postma N, Casparie M, Herings RM, Hogendoorn PC. Incidence of gastrointestinal stromal tumours is underestimated: results of a nation-wide study. Eur $\mathrm{J}$ Cancer 2005;41:2868-2872.

2. Reddy P, Boci K, Charbonneau C. The epidemiologic, healthrelated quality of life, and economic burden of gastrointestinal stromal tumours. J Clin Pharm Ther 2007;32:557-565.

3. Rubin BP, Heinrich MC, Corless CL. Gastrointestinal stromal tumour. Lancet 2007;369:1731-1741.

4. Corless CL, Barnett CM, Heinrich MC. Gastrointestinal stromal tumours: origin and molecular oncology. Nat Rev Cancer 2011;11:865-878

5. Demetri GD, von Mehren M, Antonescu CR, DeMatteo RP, Ganjoo KN, Maki RG, Pisters PWT. NCCN Task Force report: update on the management of patients with gastrointestinal stromal tumors. J Natl Compr Canc Netw 2010;8:S1-S41.

6. DeMatteo RP, Lewis JJ, Leung D, Mudan SS, Woodruff JM, Brennan MF. Two hundred gastrointestinal stromal tumors: recurrence patterns and prognostic factors for survival. Ann Surg 2000;231:51-58.

7. Eisenberg BL, Judson I. Surgery and imatinib in the management of GIST: emerging approaches to adjuvant and neoadjuvant therapy. Ann Surg Oncol 2004;11:465-475.

8. Demetri GD, von Mehren M, Blanke CD, Van den Abbeele AD, Eisenberg B, Roberts PJ, Heinrich MC, Tuveson DA, Singer S, Janicek M, Fletcher JA, Silverman SG, Silberman SL, Capdeville R, Kiese B, Peng B, Dimitrijevic S, Druker BJ, Corless C, Fletcher $\mathrm{CD}$, Joensuu $\mathrm{H}$. Efficacy and safety of imatinib mesylate in advanced gastrointestinal stromal tumors. N Engl J Med 2002;347:472-480.

9. van Oosterom AT, Judson I, Verweij J, Stroobants S, Donato di Paola E, Dimitrijevic S, Martens M, Webb A, Sciot R, Van Glabbeke M, Silberman S, Nielsen OS. Safety and efficacy of imatinib (STI571) in metastatic gastrointestinal stromal tumours: a phase I study. Lancet 2001;358:1421-1423.

10. Verweij J, Casali PG, Zalcberg J, LeCesne A, Reichardt P, Blay JY, Issels R, van Oosterom A, Hogendoorn PC, Van Glabbeke M, Bertulli R, Judson I. Progression-free survival in gastrointestinal stromal tumours with high-dose imatinib: randomised trial. Lancet 2004:364:1127-1134.

11. Blanke CD, Rankin C, Demetri GD, Ryan CW, von Mehren M, Benjamin RS, Raymond AK, Bramwell VH, Baker LH, Maki RG, Tanaka M, Hecht JR, Heinrich MC, Fletcher CD, Crowley JJ, Borden EC. Phase III randomized, intergroup trial assessing imatinib mesylate at two dose levels in patients with unresectable or metastatic gastrointestinal stromal tumors expressing the kit receptor tyrosine kinase: S0033. J Clin Oncol 2008;26:626-632.

12. DeMatteo RP, Ballman KV, Antonescu CR, Maki RG, Pisters PW, Demetri GD, Blackstein ME, Blanke CD, von Mehren M, Brennan MF, Patel S, McCarter MD, Polikoff JA, Tan BR, Owzar K. Adjuvant imatinib mesylate after resection of localised, primary gastrointestinal stromal tumour: a randomised, double-blind, placebo-controlled trial. Lancet 2009;373:1097-1104.

13. Joensuu H, Eriksson M, Sundby Hall K, Hartmann JT, Pink D, Schutte J, Ramadori G, Hohenberger P, Duyster J, Al-Batran SE, Schlemmer M, Bauer S, Wardelmann E, Sarlomo-Rikala M, Nilsson B, Sihto H, Monge OR, Bono P, Kallio R, Vehtari A, Leinonen M, Alvegård T, Reichardt P. One vs three years of adjuvant imatinib for operable gastrointestinal stromal tumor: a randomized trial. JAMA 2012;307:1265-1272

14. National Comprehensive Cancer Network ${ }^{\circledR}$ (NCCN) (2012) NCCN Clinical Practice Guidelines in Oncology ${ }^{\mathrm{TM}}$ : Soft Tissue Sarcoma. National Comprehensive Cancer Network ${ }^{\circledR}$. http:// www.ncen.org/professionals/physician_gls/pdf/sarcoma.pdf. Accessed February 29, 2012.
15. Miettinen M, Lasota J. Gastrointestinal stromal tumors: review on morphology, molecular pathology, prognosis, and differential diagnosis. Arch Pathol Lab Med 2006;130:1466-1478.

16. Chourmouzi D, Sinakos E, Papalavrentios L, Akriviadis E, Drevelegas A. Gastrointestinal stromal tumors: a pictorial review. J Gastrointestin Liver Dis 2009;18:379-383.

17. Nilsson B, Bümming P, Meis-Kindblom JM, Odén A, Dortok A, Gustavsson B, Sablinska K, Kindblom LG. Gastrointestinal stromal tumors: the incidence, prevalence, clinical course, and prognostication in the preimatinib mesylate era - a population-based study in western Sweden. Cancer 2005;103:821-829.

18. Hersh MR, Choi J, Garrett C, Clark R. Imaging gastrointestinal stromal tumors. Cancer Control 2005;12:111-115.

19. Rutkowski P, Bylina E, Wozniak A, Nowecki ZI, Osuch C, Matlok M, Switaj T, Michej W, Wronski M, Gluszek S, Kroc J, Nasierowska-Guttmejer A, Joensuu H. Validation of the Joensuu risk criteria for primary resectable gastrointestinal stromal tumour - the impact of tumour rupture on patient outcomes. Eur J Surg Oncol 2011;37:890-896.

20. Kang YN, Jung HR, Hwang I. Clinicopathological and immunohistochemical features of gastointestinal stromal tumors. Cancer Res Treat 2010;42:135-143.

21. Emile JF, Scoazec JY, Coindre JM. [Gastrointestinal stroma tumors (GIST): what is new in 2009?]. Ann Pathol 2009;29:20-23.

22. Sepe PS, Brugge WR. A guide for the diagnosis and management of gastrointestinal stromal cell tumors. Nat Rev Gastroenterol Hepatol 2009;6:363-371.

23. Hwang JH, Saunders MD, Rulyak SJ, Shaw S, Nietsch H, Kimmey MB. A prospective study comparing endoscopy and EUS in the evaluation of GI subepithelial masses. Gastrointest Endosc 2005;62:202-208.

24. Brand B, Oesterhelweg L, Binmoeller KF, Sriram PV, Bohnacker S, Seewald S, De Weerth A, Soehendra N. Impact of endoscopic ultrasound for evaluation of submucosal lesions in gastrointestinal tract. Dig Liver Dis 2002;34:290-297.

25. Palazzo L, Landi B, Cellier C, Cuillerier E, Roseau G, Barbier JP. Endosonographic features predictive of benign and malignant gastrointestinal stromal cell tumours. Gut 2000;46:88-92.

26. The ESMO/European Sarcoma Network Working Group. Gastrointestinal stromal tumors: ESMO Clinical Practice Guidelines for diagnosis, treatment and follow-up. Ann Oncol 2012;23:vii49-vii55.

27. Faigel DO, Abulhawa S. Gastrointestinal stromal tumors: the role of the gastroenterologist in diagnosis and risk stratification. J Clin Gastroenterol 2012;46:629-636.

28. Sepe PS, Moparty B, Pitman MB, Saltzman JR, Brugge WR. EUSguided FNA for the diagnosis of GI stromal cell tumors: sensitivity and cytologic yield. Gastrointest Endosc 2009;70:254-261.

29. Hoda KM, Rodriguez SA, Faigel DO. EUS-guided sampling of suspected GI stromal tumors. Gastrointest Endosc 2009;69:12181223.

30. Casali PG, Blay JY. Gastrointestinal stromal tumours: ESMO Clinical Practice Guidelines for diagnosis, treatment and follow-up. Ann Oncol 2010;21 Suppl 5:v98-v102.

31. Chu YY, Lien JM, Ng SC, Chen TC, Chen PC, Chiu CT. Endoscopic ultrasound-guided Tru-Cut biopsy for diagnosis of gastrointestinal stromal tumors. Hepatogastroenterology 2010;57:1157-1160.

32. Chaudhry UI, DeMatteo RP. Advances in the surgical management of gastrointestinal stromal tumor. Adv Surg 2011;45:197-209.

33. Ghanem N, Altehoefer C, Furtwängler A, Winterer J, Schäfer O, Springer O, Kotter E, Langer M. Computed tomography in gastrointestinal stromal tumors. Eur Radiol 2003;13:1669-1678.

34. Kalkmann J, Zeile M, Antoch G, Berger F, Diederich S, Dinter D, Fink C, Janka R, Stattaus J. Consensus report on the radiological management of patients with gastrointestinal stromal tumours (GIST): recommendations of the German GIST Imaging Working Group. Cancer Imaging 2012;12:126-135. 
35. Yang BL, Gu YF, Shao WJ, Chen HJ, Sun GD, Jin HY, Zhu X. Retrorectal tumors in adults: magnetic resonance imaging findings. World J Gastroenterol 2010;16:5822-5829.

36. Watabe T, Tatsumi M, Watabe H, Isohashi K, Kato H, Yanagawa M, Shimosegawa E, Hatazawa J. Intratumoral heterogeneity of F-18 FDG uptake differentiates between gastrointestinal stromal tumors and abdominal malignant lymphomas on PET/CT. Ann Nucl Med 2012;26:222-227.

37. Otomi Y, Otsuka H, Morita N, Terazawa K, Furutani K, Harada M, Nishitani H. Relationship between FDG uptake and the pathological risk category in gastrointestinal stromal tumors. J Med Invest 2010;57:270-274.

38. Van den Abbeele AD, Gatsonis C, de Vries DJ, Melenevsky Y, SzotBarnes A, Yap JT, Godwin AK, Rink L, Huang M, Blevins M, Sicks J, Eisenberg B, Siegel BA. ACRIN 6665/RTOG 0132 phase II trial of neoadjuvant imatinib mesylate for operable malignant gastrointestinal stromal tumor: monitoring with $18 \mathrm{~F}-\mathrm{FDG}$ PET and correlation with genotype and GLUT4 expression. J Nucl Med 2012;53:567-574.

39. McAuliffe JC, Hunt KK, Lazar AJ, Choi H, Qiao W, Thall P, Pollock RE, Benjamin RS, Trent JC. A randomized, phase II study of preoperative plus postoperative imatinib in GIST: evidence of rapid radiographic response and temporal induction of tumor cell apoptosis. Ann Surg Oncol 2009;16:910-919.

40. Miettinen M, Lasota J. Gastrointestinal stromal tumors: pathology and prognosis at different sites. Semin Diagn Pathol 2006;23:70-83.

41. Joensuu H, Vehtari A, Riihimaki J, Nishida T, Steigen SE, Brabec P, Plank L, Nilsson B, Cirilli C, Braconi C, Bordoni A, Magnusson MK, Linke Z, Sufliarsky J, Federico M, Jonasson JG, Dei Tos AP, Rutkowski P. Risk of recurrence of gastrointestinal stromal tumour after surgery: an analysis of pooled population-based cohorts. Lancet Oncol 2012;13:265-274.

42. Novitsky YW, Kercher KW, Sing RF, Heniford BT. Long-term outcomes of laparoscopic resection of gastric gastrointestinal stromal tumors. Ann Surg 2006;243:738-745; discussion 745-737.

43. Sexton JA, Pierce RA, Halpin VJ, Eagon JC, Hawkins WG, Linehan DC, Brunt LM, Frisella MM, Matthews BD. Laparoscopic gastric resection for gastrointestinal stromal tumors. Surg Endosc 2008;22:2583-2587.

44. Sokolich J, Galanopoulos C, Dunn E, Linder JD, Jeyarajah DR. Expanding the indications for laparoscopic gastric resection for gastrointestinal stromal tumors. JSLS 2009;13:165-169.

45. Lee IL, Lin PY, Tung SY, Shen CH, Wei KL, Wu CS. Endoscopic submucosal dissection for the treatment of intraluminal gastric subepithelial tumors originating from the muscularis propria layer. Endoscopy 2006;38:1024-1028.

46. Park YS, Park SW, Kim TI, Song SY, Choi EH, Chung JB, Kang JK. Endoscopic enucleation of upper-GI submucosal tumors by using an insulated-tip electrosurgical knife. Gastrointest Endosc 2004;59:409-415.

47. Sun S, Ge N, Wang C, Wang M, Lü Q. Endoscopic band ligation of small gastric stromal tumors and follow-up by endoscopic ultrasonography. Surg Endosc 2007;21:574-578.

48. Jeong IH, Kim JH, Lee SR, Kim JH, Hwang JC, Shin SJ, Lee KM, Hur H, Han SU. Minimally invasive treatment of gastric gastrointestinal stromal tumors: laparoscopic and endoscopic approach. Surg Laparosc Endosc Percutan Tech 2012;22:244-250.

49. Zhou PH, Yao LQ, Qin XY, Cai MY, Xu MD, Zhong YS, Chen WF, Zhang YQ, Qin WZ, Hu JW, Liu JZ. Endoscopic full-thickness resection without laparoscopic assistance for gastric submucosal tumors originated from the muscularis propria. Surg Endosc 2011;25:2926-2931

50. McCarter MD, Antonescu CR, Ballman KV, Maki RG, Pisters PW, Demetri GD, Blanke CD, von Mehren M, Brennan MF, McCall L, Ota DM, DeMatteo RP. Microscopically positive margins for primary gastrointestinal stromal tumors: analysis of risk factors and tumor recurrence. J Am Coll Surg 2012;215:53-59; discussion 59-60.
51. Cheng HL, Lee WJ, Lai IR, Yuan RH, Yu SC. Laparoscopic wedge resection of benign gastric tumor. Hepatogastroenterology 1999;46:2100-2104.

52. Nguyen NT, Jim J, Nguyen A, Lee J, Chang K. Laparoscopic resection of gastric stromal tumor: a tailored approach. Am Surg 2003;69:946-950.

53. Otani Y, Furukawa T, Yoshida M, Saikawa Y, Wada N, Ueda M, Kubota T, Mukai M, Kameyama K, Sugino Y, Kumai K, Kitajima M. Operative indications for relatively small $(2-5 \mathrm{~cm})$ gastrointestinal stromal tumor of the stomach based on analysis of 60 operated cases. Surgery 2006;139:484-492.

54. Catena F, Di Battista M, Fusaroli P, Ansaloni L, Di Scioscio V, Santini D, Pantaleo M, Biasco G, Caletti G, Pinna A. Laparoscopic treatment of gastric GIST: report of 21 cases and literature's review. J Gastrointest Surg 2008;12:561-568.

55. Lai IR, Lee WJ, Yu SC. Minimally invasive surgery for gastric stromal cell tumors: intermediate follow-up results. J Gastrointest Surg 2006;10:563-566.

56. Nguyen SQ, Divino CM, Wang JL, Dikman SH. Laparoscopic management of gastrointestinal stromal tumors. Surg Endosc 2006;20:713-716.

57. De Vogelaere K, Van Loo I, Peters O, Hoorens A, Haentjens P, Delvaux G. Laparoscopic resection of gastric gastrointestinal stromal tumors (GIST) is safe and effective, irrespective of tumor size. Surg Endosc 2012;26:2339-2345.

58. Heinrich MC, Corless CL. Gastric GI stromal tumors (GISTs): the role of surgery in the era of targeted therapy. J Surg Oncol 2005;90:195-207; discussion 207.

59. Kato M, Nakajima K, Nishida T, Yamasaki M, Nishida T, Tsutsui S, Ogiyama H, Yamamoto S, Yamada T, Mori M, Doki Y, Hayashi N. Local resection by combined laparoendoscopic surgery for duodenal gastrointestinal stromal tumor. Diagn Ther Endosc 2011;2011:645609.

60. Henckens T, Van de Putte D, Van Renterghem K, Ceelen W, Pattyn P, Van Nieuwenhove Y. Laparoendoscopic single-site gastrectomy for a gastric GIST using double-bended instruments. J Laparoendosc Adv Surg Tech A 2010;20:469-471.

61. Hirano Y, Watanabe T, Uchida T, Yoshida S, Kato H, Hosokawa O. Laparoendoscopic single site partial resection of the stomach for gastrointestinal stromal tumor. Surg Laparosc Endosc Percutan Tech 2010;20:262-264.

62. Melstrom LG, Phillips JD, Bentrem DJ, Wayne JD. Laparoscopic versus open resection of gastric gastrointestinal stromal tumors. Am J Clin Oncol 2012;35:451-454.

63. Pitsinis V, Khan AZ, Cranshaw I, Allum WH. Single center experience of laparoscopic vs. open resection for gastrointestinal stromal tumors of the stomach. Hepatogastroenterology 2007;54:606-608.

64. Nishimura J, Nakajima K, Omori T, Takahashi T, Nishitani A, Ito T, Nishida T. Surgical strategy for gastric gastrointestinal stromal tumors: laparoscopic vs. open resection. Surg Endosc 2007;21:875-878.

65. Gold JS, Gönen M, Gutiérrez A, Broto JM, García-del-Muro X, Smyrk TC, Maki RG, Singer S, Brennan MF, Antonescu CR, Donohue JH, DeMatteo RP. Development and validation of a prognostic nomogram for recurrence-free survival after complete surgical resection of localised primary gastrointestinal stromal tumour: a retrospective analysis. Lancet Oncol 2009;10:1045-1052.

66. Fletcher CD, Berman JJ, Corless C, Gorstein F, Lasota J, Longley BJ, Miettinen M, O'Leary TJ, Remotti H, Rubin BP, Shmookler B, Sobin LH, Weiss SW. Diagnosis of gastrointestinal stromal tumors: a consensus approach. Hum Pathol 2002;33:459-465.

67. Miettinen M, Makhlouf H, Sobin LH, Lasota J. Gastrointestinal stromal tumors of the jejunum and ileum: a clinicopathologic, immunohistochemical, and molecular genetic study of 906 cases before imatinib with long-term follow-up. Am J Surg Pathol 2006;30:477-489.

68. Joensuu H. Risk stratification of patients diagnosed with gastrointestinal stromal tumor. Hum Pathol 2008;39:1411-1419. 
69. (CAP) CoAP (2012) Protocol for the examination of specimens from patients with gastrointestinal stromal tumor (GIST). Based on AJCC/ UICC TNM, 7th edition. http://www.cap.org/apps/docs/committees/ cancer/cancer_protocols/2012/GIST_12protocol_3021.pdf.

70. Tielen R, Verhoef C, van Coevorden F, Gelderblom H, Sleijfer S, Hartgrink HH, Bonenkamp JJ, van der Graaf WT, de Wilt JH. Surgical treatment of locally advanced, non-metastatic, gastrointestinal stromal tumours after treatment with imatinib. Eur J Surg Oncol 2013;39:150-155.

71. Doyon C, Sidéris L, Leblanc G, Leclerc YE, Boudreau D, Dubé P. Prolonged therapy with imatinib mesylate before surgery for advanced gastrointestinal stromal tumor results of a phase II trial. Int J Surg Oncol 2012;2012:761576.

72. Koontz MZ, Visser BM, Kunz PL. Neoadjuvant imatinib for borderline resectable GIST. J Natl Compr Canc Netw 2012;10:1477-1482.

73. Tielen R, Verhoef C, van Coevorden F, Gelderblom H, Sleijfer S, Hartgrink HH, Bonenkamp JJ, van der Graaf WT, de Wilt JH. Surgery after treatment with imatinib and/or sunitinib in patients with metastasized gastrointestinal stromal tumors: is it worthwhile? World J Surg Oncol 2012;10:111.

74. Turley RS, Peng PD, Reddy SK, Barbas AS, Geller DA, Marsh JW, Tsung A, Pawlik TM, Clary BM. Hepatic resection for metastatic gastrointestinal stromal tumors in the tyrosine kinase inhibitor era. Cancer 2012;118:3571-3578.

75. Nannini M, Pantaleo MA, Maleddu A, Saponara M, Mandrioli A, Lolli C, Pallotti MC, Gatto L, Santini D, Paterini P, DI Scioscio V, Catena F, Fusaroli P, Pinna AD, Tos AP, Biasco G. Duration of adjuvant treatment following radical resection of metastases from gastrointestinal stromal tumours. Oncol Lett 2012;3:677-681.

76. Rutkowski P, Nowecki Z, Nyckowski P, Dziewirski W, Grzesiakowska U, Nasierowska-Guttmejer A, Krawczyk M, Ruka W. Surgical treatment of patients with initially inoperable and/or metastatic gastrointestinal stromal tumors (GIST) during therapy with imatinib mesylate. J Surg Oncol 2006;93:304-311.

77. DeMatteo RP, Maki RG, Singer S, Gonen M, Brennan MF, Antonescu CR. Results of tyrosine kinase inhibitor therapy followed by surgical resection for metastatic gastrointestinal stromal tumor. Ann Surg 2007;245:347-352.

78. Bauer S, Gronchi A, van Coervorden F, Hohenberger P, Fumagalli E, Siedlecki J, Casali PG, Treckmann J, Rutkowski P, Nyckowski P, Hoiczyk M, Cats A, Casali PG. Long-term follow-up of patients with GIST undergoing metastasectomy in the era of imatinib - an EORTC-STBSG collaborative analysis of prognostic factors. Eur J Cancer 2011;CTOS Suppl:abstract 23.

79. Eisenberg BL, Harris J, Blanke CD, Demetri GD, Heinrich MC, Watson JC, Hoffman JP, Okuno S, Kane JM, von Mehren M. Phase
II trial of neoadjuvant/adjuvant imatinib mesylate (IM) for advanced primary and metastatic/recurrent operable gastrointestinal stromal tumor (GIST): early results of RTOG 0132/ACRIN 6665. J Surg Oncol 2009;99:42-47.

80. Wang D, Zhang Q, Blanke CD, Demetri GD, Heinrich MC, Watson JC, Hoffman JP. Phase II trial of neoadjuvant/adjuvant imatinib mesylate for advanced primary and metastatic/recurrent operable gastrointestinal stromal tumors: long-term follow-up results of Radiation Therapy Oncology Group 0132. Ann Surg Oncol 2012;19:1074-1080.

81. Park S, Ryu M-H, Ryoo B-Y, Sohn B, Kim K-H, Oh S, Yu C, Yook J, Kim B, Kang Y-K. The role of surgical resection following imatinib treatment in patients with metastatic or recurrent GIST. J Clin Oncol 2012;30:abstract 62.

82. Clancy TV, Moore PM, Ramshaw DG, Kays CR. Laparoscopic excision of a benign gastric tumor. J Laparoendosc Surg 1994:4:277-280.

83. Wolfsohn DM, Savides TJ, Easter DW, Lyche KD. Laparoscopyassisted endoscopic removal of a stromal-cell tumor of the stomach. Endoscopy 1997;29:679-682.

84. Cueto J, Vázquez-Frias JA, Castañeda-Leeder P, Baquera-Heredia J, Weber-Sánchez A. Laparoscopic-assisted resection of a bleeding gastrointestinal stromal tumor. JSLS 1999;3:225-228.

85. Otani Y, Ohgami M, Igarashi N, Kimata M, Kubota T, Kumai K, Kitajima M, Mukai M. Laparoscopic wedge resection of gastric submucosal tumors. Surg Laparosc Endosc Percutan Tech 2000;10:19-23.

86. Karakousis GC, Singer S, Zheng J, Gonen M, Coit D, DeMatteo $\mathrm{RP}$, Strong VE. Laparoscopic versus open gastric resections for primary gastrointestinal stromal tumors (GISTs): a size-matched comparison. Ann Surg Oncol 2011;18:1599-1605.

87. Moriyama H, Ishikawa N, Kawaguchi M, Hirose K, Watanabe G. Robot-assisted laparoscopic resection for gastric gastrointestinal stromal tumor. Surg Laparosc Endosc Percutan Tech 2012;22:e155-156.

88. Buchs NC, Bucher P, Pugin F, Hagen ME, Morel P. Robot-assisted oncologic resection for large gastric gastrointestinal stromal tumor: a preliminary case series. J Laparoendosc Adv Surg Tech A 2010;20:411-415.

89. Liao JM, Mayer WA, Kim MM, Link RE. Robot-assisted laparoscopic excision of a pelvic extragastrointestinal stromal tumor: a case report and literature review. Can J Urol 2011;18:5731-5734.

90. Atallah S, Albert M, Larach S. Transanal minimally invasive surgery: a giant leap forward. Surg Endosc 2010;24:2200-2205.

91. Tang CM, Metildi C, Kaushal S, Leonard SY, Magistri P, Horgan S, Hoffman RM, Bouvet M, Sicklick JK. First method for in vivo fluorescent visualization of GIST. Ann Surg Oncol 2013;1:abstr S69. 